\title{
A multicenter evaluation of the Abbott RealTime HCV genotype II assay
}

Marco Ciotti', Fulvia Milano ${ }^{2}$, Mosè Favarato ${ }^{3}$, Federico Chiodo ${ }^{4}$, Franceso Renato Pulvirenti' ${ }^{5}$, Carlo Federico Perno'

I Laboratorio di Virologia Molecolare, Policlinico Tor Vergata, Roma

2 Laboratorio di Microbiologia, Ospedale S. Andrea, Vercelli

3 U.O. Biologia Molecolare ULSS 13, Mirano

4 Laboratorio di Microbiologia e Virologia, Ospedale Ca' Granda Niguarda, Milano

5 Abbott Molecular, Roma

Key words: HCV, genotype, real-time PCR

Valutazione multicentrica di un nuovo dosaggio in real-time per la determinazione del genotipo HCV

\section{SUMMARY}

Viral genotype is an important determinant of the therapeutical outcome of the chronic hepatitis $C$ and is useful in clinical practice to determine the duration of treatment'. While the viral type shows a clear association with therapeutic success, there is currently no evidence to that effect for HCV subtype, whose value is thus confined to epidemiological studies. The Abbott RealTime HCV Genotype II assay, through the use of Minor Groove Binder probes (MGB) is able to distinguish genotypes I to 6 (target 5'-UTR region) and subtypes Ia and Ib (NS5B region). In four different Italian centers a comparison between the Abbott RealTime HCV Genotype II assay and the Versant HCV Genotype 2.0 (LIPA) has been performed. A total of 143 non selected samples with the request of HCV genotyping have been analysed.

I4I/I43 samples (98.6\%) have provided reportable results with both tests ( 2 indeterminates with LIPA). Concordance at the type level was $96.5 \%$ $(|36 /| 4 \mid)$. Considering the 136 concordant samples, the distribution was as follows: type I = 6I (44.9\%), $2=36(26.5 \%), 3=2 I(I 5.4 \%), 4=17$ $(12.5 \%) 5=I(0.7 \%)$. Both assays assigned subtype in $56 / 6 I$ (9I.8\%) samples of genotype I ( 3 and 2 samples only provided the type for LIPA and Abbott, respectively) and 50/56 (89.3\%) had concordant subtype. It is worth to note that 4 of the 5 samples with discordant subtype Abbott $\mathrm{Ia} / \mathrm{LiPA} \mathrm{Ib}$ came from the only center that used for LIPA the 5-UTR amplicon, loosing the benefit of the core region which has been introduced in the version 2 of the test to improve the accuracy in distinguishing between Ia and Ib. There was only one discordant sample at type level (Abbott 4, LIPA Ib) which after sequencing and phylogenetic analysis was resolved as type 4. Four mixed infections were detected, 3 with the Abbott test (two la+4 and one Ib+3) and I with the LIPA test (la+3). In all cases the comparison test showed a single genotype I infection.

The new Abbott RealTime HCV Genotype II assay showed a high correlation with the Versant HCV Genotype 2.0 assay (LIPA). The automation platform m2000 system (Abbott), together with objective interpretation and digital archiving results may be particularly advantageous for the laboratory.

Il genotipo virale è un importante determinante virologico degli esiti della terapia dell'epatite cronica $\mathrm{C}$ ed è utile nella pratica clinica per stabilire la durata del trattamento. Mentre il tipo virale mostra una chiara associazione con il successo terapeutico, non vi sono al momento evidenze in tal senso per il sottotipo, la cui utilità rimane dunque confinata a studi di natura epidemiologica. Il dosaggio Abbott RealTime HCV Genotype II, mediante l'uso di sonde MGB (Minor Groove Binder) è in grado di distinguere i genotipi da 1 a 6 (regione target 5'-UTR) e i sottotipi 1a e 1b (regione NS5B) (Figura I, II e III). Abbiamo effettuato in quattro differenti centri italiani un confronto tra il test Abbott RealTime e il test Versant HCV Genotype 2.0 (LiPA)

La tecnologia MGB consente di utilizzare probes corti che tollerano meno i mismatches e quindi in grado di rilevare cambiamenti di una singola base. La combinazione dei pro-

\begin{tabular}{|c|c|}
\hline Strumenti & Completa sutomazione con m2000sp e m2000rt \\
\hline Confligurazione del wit & $1 \times 24$ tostsikit \\
\hline Teenologis & Real-time PCR (MGE-TaqAlan Probes) \\
\hline Sensibilits & $\leq 500101 \mathrm{~mL}(0,5 \mathrm{~mL}) \quad 0 \leq 1.250$ IUimL $(0,2 \mathrm{~mL})$ \\
\hline Specifieita & $100 \%$ \\
\hline Regioni Target & S'UTR • NSSB \\
\hline Rilevazione dei genotipi & 1a (NS5b), 1b (NS5b), 1, 2, 3, 4, 5, 6 \\
\hline Tipe di campione & Siero, Plasma (ACD-A, CPD, K-EDTA, Na-EDTA) \\
\hline Volume iniziale & $0,5 \mathrm{~mL} 00.2 \mathrm{~mL}$ \\
\hline Controllo interno & $\begin{array}{l}\text { Armored RNA (co-estratto) } \\
\text { (gene idrossipiruvato reduttasi di curcubvta pepo) }\end{array}$ \\
\hline Controlli esterni & $\begin{array}{l}\text { Controllo Negativo e Controllo Positivo } \\
\text { (5.000 iUml di GT } 1 \mathrm{e} \text { GT } 4 \text { armored RNA in plasma } \\
\text { umano negntivo) }\end{array}$ \\
\hline $\begin{array}{l}\text { Controlle della } \\
\text { contaminazione }\end{array}$ & $\begin{array}{l}\text { Reazione di PCR in fase omogena con lettura in plastra } \\
\text { sigillata + UNG }\end{array}$ \\
\hline
\end{tabular}

Caratteristiche test Abbott RealTime HCV Genotype II bes Taqman con MGB è utile per i test che richiedono elevata specificità e potere discriminatorio.

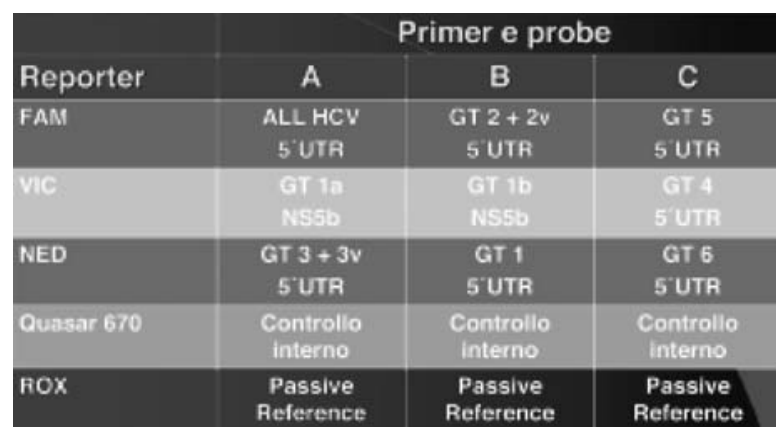

Configurazione reagenti test Abbott RealTime HCV Genotype II

Sono stati analizzati in totale 143 campioni non selezionati afferenti ai centri con la richiesta di genotipizzazione HCV.

$141 / 143$ campioni $(98.6 \%)$ hanno fornito un risultato riportabile per entrambi $\mathrm{i}$ test $(2$ indeterminati con LiPA). La concordanza a livello di tipo è stata del $96.5 \%$ (136/141). Considerando i 136 concordanti, la distribuzione era la seguente: tipo $1=61(44.9 \%) ; 2=36(26.5 \%)$; $3=21(15.4 \%) ; 4=17(12.5 \%) ; 5=1(0.7 \%)$. Entrambi i dosaggi assegnavano il sottotipo in 56/61(91.8\%) campioni di genotipo 1 ( 3 e 2 campioni fornivano solo il tipo per Abbott e LiPA rispettivamente) e 50/56 (89.3\%) avevano sottotipo concordante. Degno di nota che 4 dei 5 campioni con sottotipo discordante Abbott 1a/LiPA 1b provenivano dall'unico centro che ha impiegato

\section{Corresponding author: Marco Ciotti}

Laboratory of Molecular Virology, Foundation Polyclinic Tor Vergata,

Viale Oxford 8I-00I33 Rome, Italy - Tel.: +39 06 20902087; Fax: +39 06 20902078;

E-mail: marco.ciotti@ptvonline.it 
per il LIPA un amplificato 5'-UTR, perdendo il beneficio della regione core, appositamente introdotta nella versione 2 del test per migliorarne l'accuratezza nella distinzione tra $1 \mathrm{a}$ e $1 \mathrm{~b}$. Vi era un solo campione discordante a livello di tipo (Abbott 4, LiPA 1b) che dopo sequenziamento e analisi filogenetica mostrava un "cluster" di tipo 4. Sono state evidenziate 4 infezioni miste, 3 con il test Abbott (due $1 \mathrm{a}+4$ e una $1 b+3)$ e 1 con il test LiPA $(1 a+3 a)$. In tutti i casi il test di confronto mostrava una monoinfezione con il corrispondente genotipo 1.

Il nuovo dosaggio Abbott RealTime HCV Genotype II ha mostrato un'elevata concordanza con il test Versant HCV Genotype 2.0 (LiPA). L'automazione sulla piattaforma $\mathrm{m} 2000$ System (Abbott), unitamente all'interpretazione oggettiva

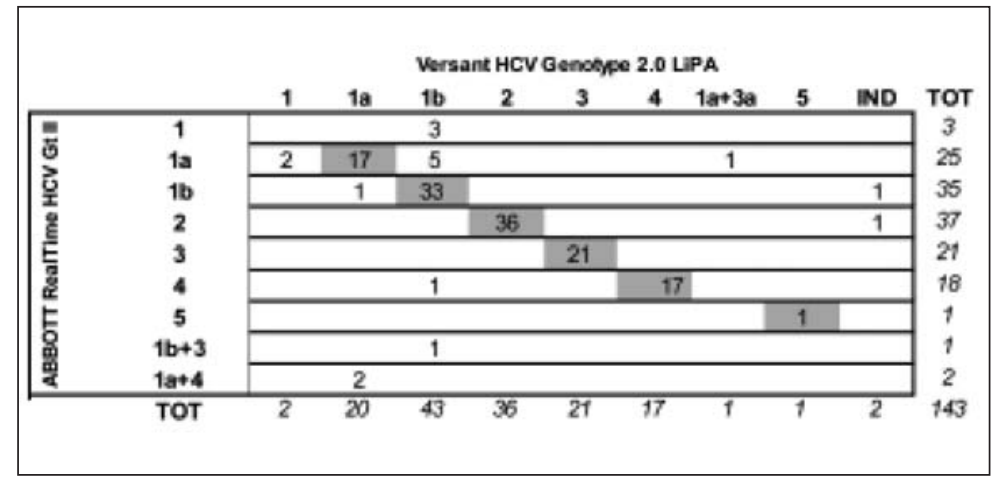

Confronto dei risultati LiPA e Abbott

e all'archiviazione digitale dei risultati possono risultare particolarmente vantaggiose per il laboratorio.

\section{BIBLIOGRAFIA}

1. Hnatyszyn HJ. Chronic hepatitis $\mathrm{C}$ and genotyping: the clinical significance of determining HCV genotypes. Antivir Ther. 2005; 10: 1-11.

2. Bouchardeau F, Cantaloube JF, Chevaliez S, et al. Improvement of hepatitis $\mathrm{C}$ virus (HCV) genotype determination with the new version of the

Inno-LiPA HCV Assay. J Clin Microbiol 2007; 45: 1140-5

3. Kuiken C, Simmonds P. Nomenclature and numbering of the hepatitis $\mathrm{C}$ virus. Methods Mol Biol 2009; 510: 33-53. 